\title{
Are we looking to stroke and quality of life?
}

\begin{abstract}
Abbrevations: QoL, quality of life; HRQoL, health related quality of life; DALYs, disability-adjusted years of life; WHO, world health organization; QALYs, quality-adjusted life-year; GBD, global burden of disease, YLDs, years of life lived with disability; SSQoL, stroke specific quality of life scale; NIHSS, national institute of health stroke scale; BI, barthel index
\end{abstract}

\section{Quality-of-life}

Etymologically, the term quality derives from "qualis" (latin), which means the standard of health, comfort, and happiness experienced by an individual (itself) or related to group. It can assume positive or negative meanings. ${ }^{1}$ Since the 1970 s, the term "quality of life" (QoL), as an objective measure of health outcome, has been used in epidemiological studies as an end point for social indicators, positive psychology, and mainly for the humanization of medicine. ${ }^{2}$ From the 1990s, some authors observed that in the concept of the term of QoL were two important aspects to be added-the subjectivity (the perception of all aspects of $\mathrm{QoL}$ ) and the multidimensionality (recognition that the construct is composed of different dimensions)..$^{3,4}$ In view of the different concepts in the literature, a group of World Health Organization (WHO) researchers decided to cover all and defined it as the "perception of the individual about his position in life, in the context of the culture and system of values in which he lives, and in relation to his goals, expectations, standards and concerns ". This is the latest definition.

Regarding to the health area, two conceptualizations were observed-QoL as a more generic concept (influenced by sociological studies, without referring to dysfunctions or injuries) and health related quality of life (HRQoL) related to diseases or health interventions. ${ }^{3,4}$ The term HRQoL, currently used, evaluates the patient's perception in four dimensions: 1) physical, 2) functional, 3) psychological and 4) social. Also encompassing personal beliefs, religiosity and spirituality ${ }^{6}$

\section{Stroke and quality of life}

Stroke is a highly disabling disease. More than the numbers of mortality, the incapacity or morbidity related to stroke open an important discussion about the relation between stroke and QoL. In the literature, one of the ways to evaluate HRQoL is to use HALYs (health-adjusted life years). These is a measure of life expectancy with measures of QoL in an illness, including quality-adjusted life-year(QALYs) and disability-adjusted years of life (DALYs).

DALYs were introduced in the 1990s in the Global Burden of Disease (GBD) study at the World Bank's request in collaboration with the WHO. These are the sum of the years of life lost due to premature mortality (YLLs) and years of life lived with disability (YLDs), adjusted for the severity of the disability. The measure of severity ranges from " 0 " (which is perfect health or normal health) to " 1 " (which is the weight of a health condition equivalent to death or worse health possible). Time lost due to premature mortality was discounted $3 \%$ a year, so that a year of life lost in the future is less valuable than a year of lost life today. ${ }^{8,9}$ There are some data on stroke DALYs that reinforce the idea of QoL impairment in cerebrovascular disease. These studies classify stroke through the National Institute of Health Stroke Scale (NIHSS) as severe (NIHSS $>17$ ), moderate (NIHSS $<16$ and $>8$ ) and minor (NIHSS $<8$ ), or through the modified Rankin Scale (mRS) that rating independence as major (mRS 4 and 5)
Volume 4 Issue 4 - 2019

Viviane Flumignan Zetola, Camila Thieime Rosa

Department of Neurology, Federal University of Parana, Brazil

Correspondence: Viviane Flumignan Zétola, Department of Neurology, Clinical Hospital, Federal University of Parana, |8| General Carneiro Street, 4o floor ZIP 80060-900 - Curitiba, PR, Brazil,Tel (55) 4I3264-7500,Email viviane.zetola@gmail.com

Received: July 03, 2019 | Published: August 07, 2019

and minor $(\mathrm{mRS}<3)$. In the systematic reviews and meta-analyzes the values found vary from -0.02 (indicating that major stroke is worse than death) to 0.71 for major stroke, 0,12 to 0,81 for moderate stroke and 0.45 to 0.92 for minor stroke (from 0.29 to 0.903 for general stroke). Most of the studies shows data that, despite of the use of different assessment methods in different populations, as well as the different severity levels of the event, a significant impact on QoL occurs in patients suffering from stroke. ${ }^{9-11}$

\section{The importance of evaluating the QoL in stroke}

The predictive factors reported in the literature related to QoL in post-stroke patients differ significantly in the literature, and the main differences are observed in the analyzes according to the time (period) of the evaluation, with functional status, social factors and psychological. ${ }^{12-18}$

We performed a study in a Public Hospital in Brazil where we used the Stroke Specific Quality of Life Scale (SSQoL) for QoL analysis, a well-known validate scale (also in Portuguese). We found that $30 \%$ of patients have a poor QoL after the first-ever ischemic stroke. In the stepwise model considering basic activities of daily living, we found hypertension, lack of rehabilitation, current functional status linked with the incapacity to return to work and complications after stroke were related to poor QoL. It showed to us that different aspects of life should be evaluated once it interfered with QoL. It can be lost if the tools of analysis include routine scales evaluation. We analyzed patients after 6 months of stroke. In this study, the NIHSS cutoff point which interfered with QoL was $\geq 9 .{ }^{19}$ We didn't have this information in the literature, and it should be compared with other studies.

Prognosis after stroke is an important topic to be evaluated in the studies. It can impact in treatments decisions as well have an enormous economic influence in long term treatment. Studies related to stroke prognosis ration often use the mRS, the Barthel Index (BI) and the Lawton and Body Inventory Although in some situations such tools can be correlated with the improvement of QoL the use of specific measures as a SSQoL can add information's to a better rehabilitation planning. The vision of functional recovery should be associated with global care that involves parameters of QoL. Stroke is undoubtedly the best study model to studied QoL since it is considered the most disabling disease worldwide. A more objective approach to rehabilitation which considers not only the disability assessment but also the QoL as a whole, encompassing more analytical tools, may certainly translate into better HRQoL in stroke survivors..$^{14,20-22}$ 


\section{Funding}

None.

\section{Acknowledgments}

None.

\section{Conflicts of interests}

The authors of this manuscript have no competing interests.

\section{References}

1. Pereira ÉF, Teixeira CS, Santos A. Quality of life: approaches, concepts and evaluation. Rev bras educ fis esporte. 2012; 26(2):241-250.

2. Fleck MPA. Conceptual problems in quality of life. Quality of life assessment: guide for health professionals. Porto Alegre: Artmed. 2008:19-28.

3. Seidl EMFl, Zannon CMLC. Quality of life and health: conceptual and methodological aspects. Cad Saúde Pública. 2004;20(2):580-588.

4. Gordia AP, Quadros TMB, Oliveira MTC, et al. Quality of life: historical context, definition, assessment and associated factors. Rev Bras Qual Vida. 2011;3(1):40-52.

5. The Whoqol Group. The World health organization quality of life assessment (WHOQOL): position paper from the world health organization. Soc Sci Med. 1995;41:1403-1410.

6. Oliveira MR, Orsini M. Quality of life assessment scales in Brazilian patients after stroke. Rev Neurocienc. 2009;17(3):255-262.

7. Tseng MC, Lin HJ. Health-related quality of life after stroke: Review of the literature and implications for future research. Acta Neurol Taiwan.2007; 16:7-12.

8. Murray CJL, Lopez AD. Evidence-based health policy: lessons from the global burden of disease study. Science. 1996; 274:740-743.

9. Tengs TO, Lin TH. A meta-analysis of quality-of-life estimates for stroke Pharmacoeconomics. 2003;21:191-200.

10. Tengs TO, Yu M, Luistro E. Health-related quality of life after stroke: a comprehensive review. Stroke. 2001;32:964-972.
11. Post PN, Stiggelbout AM, Wakker PP. The utility of health states after stroke. A systematic review of the literature. Stroke. 2001;32:1425-1429.

12. Carod-Artal J, Egido JA, Gonzalez JL, et al. Quality of life among stroke survivors evaluated 1 year after stroke: experience of a stroke unit. Stroke. 2000 Dec;31(12):2995-3000.

13. Wang RBL. Predictors of quality of life for chronic stroke survivors in relation to cultural differences: a literature review. Scand J Caring Sci. 2018;32(2):502-514.

14. Carod-Artal FJ, Trizotto DS, Coral LF, et al. Determinants of quality of life in Brazilian stroke survivors. J Neurol Sci. 2009;284(1-2):63-68

15. Jaracz K, Kozubski W. Quality of life in stroke patients. Acta Neurol Scand. 2003;107(5):324-329.

16. Jonsson AC, Lindgren I, Hallstrom B, et al. Determinants of quality of life in stroke survivors and their informal caregivers. Stroke. 2005;36(4):803808.

17. Gunaydin R, Karatepe AG, Kaya T, et al. Determinants of quality of life (QoL) in elderly stroke patients: a short-term follow-up study. Arch Gerontol Geriatr. 2011 Jul-Aug;53(1):19-23.

18. Moreira NRTL, Andrade A, Ribeiro K, et al. Qualidade de vida em indivíduos acometidos por Acidente Vascular Cerebral. Rev Neurocienc. 2015;23(4):530-537.

19. Rosa CT, Zonta MB, Lange MC, et al. Is There Quality of Life after Stroke in developing country?. In press. 2019.

20. Mutai H, Furukawa T, Nakanishi K, et al. Longitudinal functional changes, depression, and health-related quality of life among stroke survivors living at home after inpatient rehabilitation. Psychogeriatrics. 2016;16(3):185-190.

21. Vincent OGO, Hamzat TK, Owolabi MO. Consistent determinants of health-related quality of life in the first 12 months after stroke: a prospective study in Nigeria. Top Stroke Rehabil. 2015;22:127-133.

22. Aprile I, Piazzini DB, Bertolini C, et al. Predictive variables on disability and quality of life in stroke outpatients undergoing rehabilitation. Neurol Sci. 2006;27:40-46. 